\title{
La creatividad performativa
}

\section{Resumen}

En este artículo se discuten algunos planteamientos que constituyen la creatividad performativa, los cuales hacen parte de la tesis de doctorado "Umbrales de la Creatividad". El abordaje metodológico cualitativo de tipo émico, posibilitó un discurso en torno a la "creatividad situada" como constructo social de conocimiento. Constituye un ejercicio de reflexión a partir de las retóricas que los Drag Queen utilizan para visibilizar su mundo. Nos habla, en particular, del estilo de Zaza-Drag, de su experiencia de mundo, de su condición humana y de la apariencia de los Zapatos Drag Queen. Explicita la naturaleza de la "jugada performativa" de Zaza-Drag (Drag Valeri-Zaza) en cuatro resultados: "entre lo público y lo privado", "Ilamar la atención" y lo "sencillo pero exagerado", derivando en la condición "evocativa y performativa de los Zapatos".

\author{
Samuel Alberto \\ Herrera-Castiblanco \\ Doctor en Ingeniería \\ Investigador - profesor de la \\ Universidad Nacional de \\ Colombia, sede Bogotá \\ Bogotá, Colombia \\ Correo electrónico: \\ saherrerac@unal.edu.co \\ ๑ o orcid.org/0000-0001-8948-5427 \\ Google Scholar
}

Recibido: marzo 11 de 2019

Aprobado: octubre 30 de 2020

Palabras clave:

Drag Queen, Identidad,

Creatividad Situada, Performance, Zapatos. 


\section{Creative Performance}

\begin{abstract}
This article discusses some approaches that constitute performative creativity which are part of the doctoral Thesis Requirement "Thresholds of Creativity". The qualitative methodological approach of an emic type, made a discourse around the "Situated creativity" as a social construct of knowledge. It is a reflexive exercise based on the rhetoric that Drag Queens use to make their world visible. It particularly deals with the Zaza-Drag's style, his experience of the world, his human condition and the appearance of the Drag Queen shoes. It makes explicit the nature of the "performative play" of Zaza-Drag (Drag Valeri-Zaza) in four result: "between the public and the private", "drawing attention", and the "simple but exaggerated," deriving in the "evocative and performative condition of Shoes".
\end{abstract}

\section{Key words:}

Drag Queen, Identity, situated Creativity, Performance, Shoes. 
Introducción

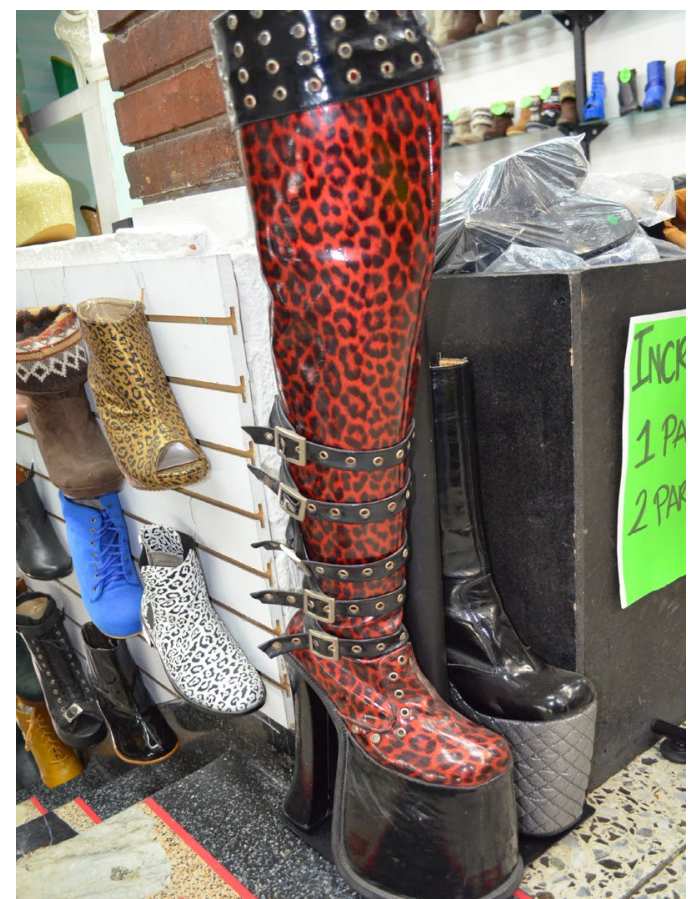

Figura 1. Zapatos Drag Queen. Fuente: propia.

La Figura 1 es una fotografía de unos zapatos para Drag Queen producidos en una micro pequeña organización productiva - Mipyme — ubicada al sur de la ciudad de Bogotá, en el barrio Restrepo, Ilamada Calzado Yara Aristizábal. Estos zapatos, para algunos exagerados, para otros triviales o cotidianos, le sirvieron a este investigador como agenciadores, favorecieron la 
problematización de la creatividad desde la perspectiva de lo performativo. Gracias a los zapatos se sitúo la creatividad en una reducida red de actores con visiones de mundo particulares (identidades), destacando la naturaleza de un Drag Queen autodenominado Drag Valeri-Zaza, en adelante Zaza-Drag y sus potenciales desempeños performativos, a partir de su particular estilo.

Es debido a los zapatos que se pudo construir sentido, en aras de seguir aportando a encontrar respuestas alternativas a aspectos tales como: ¿dónde se manifiesta la creatividad? ¿Cuál es la naturaleza de aquellos "creativos"? ¿De qué estrategias echan mano para ser creativos? Este tipo de inquietudes no intentan resolver el problema acerca de ¿qué es la creatividad? Más bien procuran aportar nuevas comprensiones en la frontera de conocimiento de la creatividad. Al problematizar la creatividad de manera situada, se está aportando a fortalecer los procesos de demarcación a partir de lo performativo. Se atienden los procesos de demarcación derivados de las discusiones de Restrepo Forero (2007):

entrañan la participación de diversos actores, instituciones y agencias en un conjunto de acciones discursivas de producción de maneras de diferenciar. Se trata de un esfuerzo activo de creación de fronteras, y de divisiones de competencias que involucran maneras de clasificar y jerarquizar; de producir definiciones normativas sobre: prácticas apropiadas (obligaciones), actores relevantes, espacios legítimos, tópicos, métodos y contenidos adecuados. (Restrepo Forero, 2007, p. 243)

El análisis de los procesos de demarcación de la creatividad, en la línea de Gieryn (1983), facilitó su comprensión como procesos retóricos y no como procesos de descubrimiento de esencias de la creatividad y sus fronteras. Así, la demarcación de la creatividad se puede entender más como una actuación política situada y no como parte de definiciones filosóficas o conceptuales abstractas. 


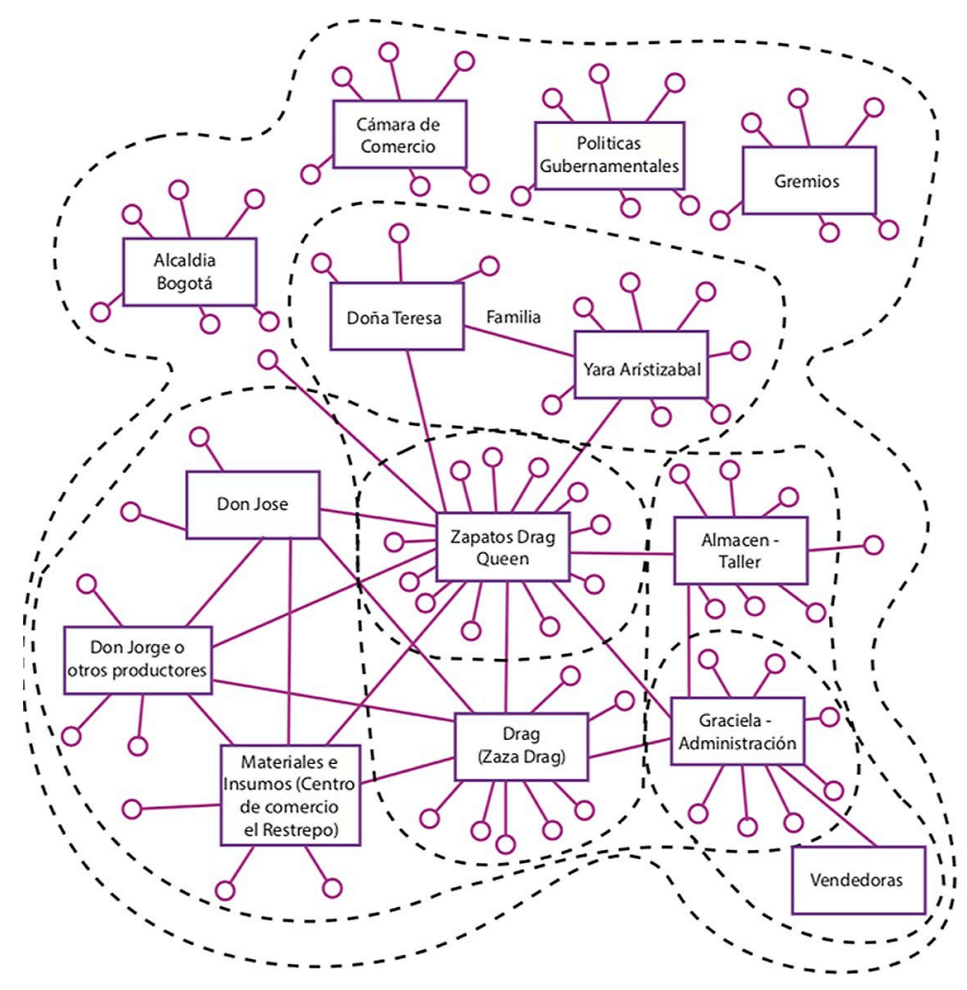

Figura 2. Red de actores Calzado Yara Aristizábal. Fuente: Propia.

El trabajo propuesto implicó realizar una especie de "cartografía" de esa red en los términos discutidos por Goyes Narváes, et al. (2017) Para ellos, cartografiar implica "mapear los territorios que componen la vida y que se entrelazan a las formas de vivir (...) se constituye como un dispositivo de análisis y creación de realidad; de suerte que la realidad no es algo inamovible, sino tejido de sentidos y prácticas por construir" (p. 45) (Véase Figura 2). 
El conocimiento creativo situado, como objeto de investigación, se instaló en la identificación de los descriptores que posibilitaron la comprensión del éxito de lo performativo de Zaza-Drag, traducido en términos de las diversas maneras como ella logra destacarse. El éxito está relacionado con la alineación de una cantidad de factores motivados por la diversidad de las galas drag, al tiempo que la búsqueda por marcar deferencias de estilo en el tiempo; ese éxito se relaciona de manera directa con lo creativo. La creatividad es otra manera de decir que se pudo resolver un problema o una crisis de manera adecuada. Por lo anterior, cabe destacar el carácter situado de la creatividad, que se revela cuando enfocamos la atención en una red sociocreativa, cuando localizamos socialmente hechos que traducen lo performativo en términos de identidad, de procurar caracterizar el estilo de un Drag Queen y de sus Zapatos. Por medio de la comprensión de las dinámicas de la construcción performativa, podemos re-crear no solamente nuevas realidades sino —en palabras de Fleck (1986, p. 145)— nuevos "estilos de pensamiento" ${ }^{1}$. El estilo de pensamiento se hace manifiesto en Zaza-Drag mediante diversas performances, que nos hablan de su trabajo en torno de la construcción de su identidad y de sus procesos de coproducción con sus "Zapatos Drag Queen".

Como se dijo anteriormente, lo performativo se perfila a partir del estilo particular de Zaza-Drag. Del análisis de dicho estilo se identifican procesos de reconversión, astucias y autenticidades que redundan en cuatro resultados destacables desde la condición de estilo. Primero, abriendo espacio a la cotidianidad de Zaza-Drag como comprensión de su relación "entre lo público y lo privado". Segundo, a partir de la identificación de la naturaleza del mundo drag y su incidencia en la constitución de las diversas retóricas que utilizan para destacarse o hacerse notar, en últimas, "llamar la atención". Tercero, la exploración de los modos que utiliza Zaza-Drag para Ilamar la atención

'Puede leerse también, como PARADIGMA. En los términos desarrollados por Kuhn, T. S. (1998). En "La estructura de las revoluciones científicas". Traducido por Agustín Contin. Santafé de Bogotá: Fondo de la cultura económica. 
en términos de "lo sencillo pero exagerado" y, por último, procurando dar respuesta al por qué son los "zapatos evocadores", explicitado desde la condición de memorabilidad.

\section{Metodología}

La metodología está constituida en tres planos: por un lado, se utilizaron metodologías de tipo cualitativo demarcando la comprensión de "situación" de la red de actores al interior de una MiPyme y por medio de un estudio de caso detallado con base en una etnografía. Acorde a los planteamientos de Hammersley y Atkinson

la etnografía es la forma más básica de la investigación social, es "observación participante". El etnógrafo, participa, abiertamente o de manera encubierta, de la vida cotidiana de las personas durante un tiempo relativamente extenso, viendo lo que pasa, escuchando lo que se dice, preguntando cosas; o sea, recogiendo todo tipo de datos accesibles para poder arrojar luz sobre los temas que él o ella han elegido estudiar. (Hammersley \& Atkinson, 1994, p. 15)

Entrevistas, registro de audio y video, acompañamientos, hicieron parte del conjunto de herramientas utilizadas para realizar un seguimiento del trabajo de campo. El abordaje permitió reconocer la naturaleza de una MiPyme y, al mismo tiempo, el carácter socio-creativo de la red de actores que la conforman y que son mediados por los Zapatos Drag Queen. Este artículo concentra la atención en un solo actor: Zaza-Drag. Cabe resaltar que este abordaje no tiene un enfoque histórico ni filosófico, sino dependiente de los diversos repertorios construidos a partir del estudio de caso. Lo empírico de la etnografía condiciona que no se puedan anticipar todos los aspectos, que se acepte de entrada que existen algunos grados de incertidumbre sobre los cuales el mismo proceso etnográfico arroje luz. En línea con Taylor y Bogdan (1987) se consolida la construcción del trabajo a partir de un enfoque primordialmente de tipo émico, 
sin descartar —en algunos aspectos de tipo reflexivo y/o crítico- el uso del enfoque ético, soportado a través de fuentes bibliográficas.

De acuerdo con el enfoque émico, la conducta social debe examinarse en los términos de las Categorías de significados (conceptos, tipologías, etcétera) de las personas que se estudian. Estas categorías de significados son conceptos de primer orden. En el enfoque ético, los investigadores aplican sus propios conceptos para entender la conducta social de las personas en estudio. Estos se denominan conceptos de segundo orden puesto que se trata de "constructos de los constructos elaborados por los lores de la escena social" (Schütz, 962, pág. 6) (...) Como nuestro examen lo indica, ambos enfoques pueden emplearse en un estudio único. (Taylor \& Bogdan, 1987, p. 162)

En el mismo sentido, Guber (2001) concibe cómo los actores no siguen reglas, las actualizan, y al hacerlo interpretan la realidad social y crean contextos en los cuales los hechos cobran sentido. Apoyarse en este tipo de proceder metodológico posibilitó caracterizar un nuevo umbral creativo a partir de lo performativo del actuar de Zaza-Drag.

De otro lado está mi perspectiva, constituida a partir de la naturaleza de las relaciones entre quien soy como diseñador industrial y lo que puedo conocer. Así las cosas, una de las primeras tareas a las que me enfrente como investigador de la creatividad tenía que ver con el encargo de mi directora de tesis de doctorado (la profesora y socióloga Olga Restrepo) en cuanto a "desinflar el concepto"; se han desarrollado cualquier cantidad de definiciones, muchas veces contradictorias, a tal punto que su abordaje no es sencillo debido a que los discursos son polisémicos y densamente estratificados o tan epidérmicos se escurren entre los dedos, su abordaje es complejo, con múltiples centros de gravitación; situar la creatividad implicó: 
- Instalarse en las realidades de una Mipyme del sector del Cuero, el Calzado y la Marroquinería, que produce Zapatos, ubicada en el barrio Restrepo de la ciudad de Bogotá denominada "Calzado Yara Aristizábal", quienes identificaron un nicho específico en el mercado Drag Queen y se han mantenido por más de 40 años a partir del diseño constante y desarrollo de un producto especializado.

- Definir los "Zapatos Drag Queen" producto característico, aun cuando los zapatos son eje unificador de los repertorios analíticos, será la performance característica de Zaza-Drag lo que permite abordar el proceso en su dinámica de coproducción de identidad.

- Caracterizar una red de actores humanos y no humanos, en torno a los "Zapatos Drag Queen".

- La identificación de aquellos descriptores diferenciados de análisis que sirven para la comprensión del carácter de lo performativo de un Drag en particular (Zaza-Drag).

El último plano para problematizar la creatividad y luego la performatividad como problemas de conocimiento, implicó pensarlas en el marco del Doctorado en Ingeniería: Industria y Organizaciones, programa de la Facultad de Ingeniería de la Universidad Nacional de Colombia (sede Bogotá), investigación que se inscribe en el área: "Investigación en epistemología de las organizaciones, la hermenéutica de la gestión y el pensamiento empresarial de la industria y las organizaciones productivas", y en la línea de investigación "sistemas y gestión de la tecnología, la información, el conocimiento y la innovación tecnológica en la industria y las organizaciones. Derivando en el trabajo de tesis de Herrera (2019). "Umbrales de la Creatividad: La construcción social de Conocimiento Creativo en algunas Micro - Pequeñas Organizaciones Productivas (Mipymes)". 


\section{Discusión en torno a la Performatividad Construida}

Lo performativo se puede comprender como constructo sociocultural. Por más que se manifieste de manera particular, esa persona o colectivo que lo origina tendrá afectaciones sociales, históricas, económicas, culturales, tecnológicas, geográficas, entre otras. Todas estas constituyen un marco de tipo contextual. Por tal razón, es necesario comprender las dinámicas que se generan entre el peso ordenado de los contextos (instituciones), junto a la riqueza y diversidad de individualidades, sus actitudes y la manera particular de cómo alinean ciertos actos contingentes. Esto quiere decir que para hablar del desempeño performativo de Zaza-Drag y de sus Zapatos Drag Queen, es necesario comprender cómo su red sociocreativa constitutiva posibilitó cierto tipo de desempeños performativos. Buena parte de estos aspectos los discute Fleck (1986) a partir de la consolidación del estilo de pensamiento.

Podemos definir el estilo de pensamiento como un percibir dirigido con la correspondiente elaboración intelectiva y objetiva de lo percibido. Queda caracterizado por los rasgos comunes de los problemas que interesan al colectivo de pensamiento, por los juicios que el pensamiento colectivo considera evidentes y por los métodos que emplea como medio de conocimiento. El estilo de pensamiento también puede ir acompañado por el estilo técnico y literario del sistema de saber. (Fleck, 1986, p. 145)

De la dinámica entre el estilo de pensamiento y el colectivo de pensamiento surgen actos contingentes de carácter performativo que se pueden denominar creativos. Cuando se profundiza lo performativo, un primer referente es Butler (2007), quien la identifica como una incorporación o fantasía hecha realidad, cuya coherencia es anhelada, esperada e idealizada, además, que esta idealización es efecto de una significación corporal. El gesto de uso, el desempeño de la tarea, la teatralidad, la exageración, son algunos de los aspectos que se han de considerar cuando nos enfocamos en un Drag Queen en particular, desde lo performativo. Butler (2007), discute lo performativo a 
partir de los efectos de los límites mediadores o estabilizadores que adquieren sentido en referencia de la relación de lo que se es (interno) con lo que se quiere o puede mostrar debido a presiones socioculturales (externo). Butler, profundiza sobre la "coherencia y estabilidad" como resultado de las maneras como los "órdenes culturales" castigan la diferencia. Pero, además, discute cómo los actos son performativos mediante signos corpóreos.

Actos, gestos y deseo crean el efecto de un núcleo interno o sustancia, pero lo hacen en la superficie del cuerpo, mediante el juego de ausencias significantes que evocan, pero nunca revelan, el principio organizador de la identidad como una causa. Dichos actos, gestos y realizaciones - por lo general interpretados - son performativos en el sentido de que la esencia o la identidad que pretenden afirmar son invenciones fabricadas y preservadas mediante signos corpóreos y otros medios discursivos. (Butler, 2007, p. 266)

Esos actos, entonces, "son performativos en el sentido que la identidad que pretenden afirmar son invenciones fabricadas mediante signos corpóreos y otros medios discursivos" (p. 266).

De otra parte, Lyotard (1994) propone una "jugada" hecha en la pragmática de los saberes, a la cual denomina "paralogía", identificando —de pasoalgunos criterios de la performatividad: sitúa el cálculo de las interacciones en el puesto de la definición de esencias; hace asumir a los "jugadores" la responsabilidad no solo de los enunciados, sino también de las reglas a los que los someten para hacerlos aceptables. Este mismo autor destaca cuatro ventajas del criterio performativo: excluye la adhesión a un discurso metafísico; requiere el abandono de las fábulas; exige mentes claras y voluntades frías; hace asumir a los jugadores la responsabilidad no solo de los enunciados sino de las reglas a las que los someten para hacerlos aceptables. Para él, la mejor Performatividad "resulta de una nueva disposición de datos, que constituyen propiamente una jugada" (p. 95). La jugada en cuestión se relaciona con el alineamiento de los actos de una manera particular, dependiente de los 
actores y del contexto, a esto le da el nombre de Parología. La paralogía hace referencia a la estrategia construida con un fin determinado. Acorde a Lyotard ésta posibilita "el reemplazamiento de la normatividad de las leyes por la Performatividad de procedimientos" (p. 86).

Lo performativo y la jugada que conlleva su constitución, están en la línea del concepto de reconversión, planteado por García Canclini (1998) cuando discute los procesos de adaptación que utilizan los campesinos y los obreros para vivir en la ciudad, sin abandonar sus creencias antiguas.

No se trata solo de las estrategias institucionales y los sectores hegemónicos. Las hallamos también en la "reconversión" económica y simbólica conque los migrantes campesinos adaptan sus saberes para vivir en la ciudad, y sus artesanías para interesar a consumidores urbanos; cuando los obreros reformulan su cultura laboral ante las nuevas tecnologías sin abandonar sus creencias antiguas, y los movimientos populares insertan sus demandas en radio y televisión. (García Canclini, 1998, p. 14)

Los procesos de reconversión nos hablan de capacidades de adaptación o traducción, implican tener disposición hacia la flexibilidad y de ajuste constante en función de las circunstancias y recursos de un momento determinado. En otras palabras, refiere a la capacidad de constituir actos contingentes, pero con acentos particulares. Dichos acentos hacen referencia, de una u otra manera, a las astucias, aspecto que nos habla de la naturaleza humana de quien estructura la performance, su visión de mundo, su vida vivida en términos de estratégicos. García Canclini reflexiona sobre el aspecto:

Como estudiar las astucias con que la ciudad intenta conciliar todo lo que le llega y prolifera, y trata de contener el desorden: el trueque del campesino con lo transnacional, los embotellamientos de coches frente a las manifestaciones de protesta, la expansión del consumo junto a las demandas de los desocupados, los duelos entre mercancías y comportamientos venidos de todas partes. (García Canclini, 1998, p. 16) 
Estamos haciendo extensivo lo performativo en términos de los procesos de reconversión y las astucias, pero queda pendiente destacar de qué manera lo performativo se manifiesta como una autenticidad que se relaciona con esa manera muy propia de resolver las cosas, en los términos planteados por Escobar (2007, p. 410): "no es raro que lo que parece práctica o arte genuino revele, en una inspección detallada, la acomodación de tipos de "autenticidad"". Si prestamos atención a esa manera "particular" de constituir actos contingentes a una situación determinada, debemos atender la naturaleza de quien los constituye. Ese carácter muy propio de la persona o de los colectivos, se resuelve desde la identidad. Esto quiere decir, que comprender lo performativo va a depender directamente de la comprensión del carácter identitario.

La identidad tiene que ver con la semejanza o la diferencia, nos habla de "ese algo" o de esa característica que distingue a una persona, un grupo o un objeto de lo que no es. Las personas y los colectivos de personas suelen identificarse a sí mismas, de paso intentan proyectar algún tipo de imagen. Es importante tener en consideración la cualificación del concepto de Bauman (2003, p. 41), "identidad" será el nombre dado a la búsqueda de salida de cierta incertidumbre. Pensamos en la identidad cuando no estamos seguros del lugar al que correspondemos, es decir, cuando no estamos seguros de cómo situarnos en la evidente variedad de estilos y pautas de comportamiento y hacer que la gente que nos rodea acepte esa situación como correcta y apropiada, a fin de que ambas partes sepan cómo actuar en presencia de la otra.

La identidad es una proyección crítica de lo que se demanda o se busca con respecto a lo que es; aún más exactamente, una afirmación indirecta de la inadecuación o el carácter inconcluso de lo que es. La identidad se incorporó a la mentalidad y la práctica modernas ataviada desde el inicio como una tarea individual. Correspondía al individuo encontrar un escape de la incertidumbre. (Bauman, 2003, p. 42) 
Para Hall (2003, p. 14), la identidad es un concepto que funciona "bajo borradura" en el intervalo entre inversión y surgimiento. Las identidades son, por así decirlo, las posiciones que el sujeto está obligado a tomar, a la vez que siempre "sabe" que son representaciones, que la representación siempre se construye a través de una "falta", una división, desde el lugar del otro, y por eso nunca puede ser adecuada —idéntica — a los procesos subjetivos investidos en ellas. De esta manera las identidades son siempre relacionales e incompletas tal y como lo expresa Grossberg, ya que siempre están en proceso:

Toda identidad depende de su diferencia y su negación de algún otro término, mientras que la identidad de este depende de su diferencia y su negación de la primera. Revela al mismo tiempo, como las luchas en torno de la identidad —entre lo público y lo privado; entre lo interno y lo externo; entre individuos de la misma comunidad, entre otras - ya no implican cuestiones de adecuación o distorsión, sino de la política misma de la representación. Vale decir que la política implica cuestionar el modo de producción y asunción de las identidades a través de las prácticas de la representación. (Grossberg, 2003, p. 153)

Lo performativo, en términos de identidad, implica la extensión comprensiva que la identidad se constituye a partir de la integración de otras identidades. Esto implica cierto tipo de "identidades múltiples" que generan perspectivas que varían y se superponen. Identificaciones múltiples y coexistentes como lo plantea Butler que "engendran conflictos, coincidencias y desacuerdos innovadores dentro de las configuraciones de género que refutan el carácter fijo de los sitios donde se sitúan lo masculino y lo femenino" (2007, p. 153). Los modos de llamar la atención de los Drag, darán cuenta de su identidad particular y de la identidad de la comunidad drag agenciada políticamente como una integración de fragmentos. En ese sentido Hall, plantea: "al decir agencia no expreso deseo alguno de volver a una noción no mediada y transparente del sujeto o de identidad como autores centrados en la práctica social" (2003, p. 14). 
En cuanto a la acción y el discurso en la constitución política de la identidad, Butler propone un inicio de la acción política en la que no es preciso que exista un "agente detrás de la acción", sino que el "agente" se construye de manera variable en la acción y a través de ella $(2007$, p. 277). Las inquietudes sobresalen de esta mirada fragmentada: ¿cómo evitar "perdernos" en medio de tanto fragmento? La respuesta la podemos encontrar con el uso de la técnica del ensamblado, en los términos planteados por Law citado por Fressoli et al.: un ensamblaje es "generativo y performativo, produce presencia y ausencia, se consolidan algunos aspectos para la fabricación de las relaciones en: aquello que está presente (una representación o un objeto); cualquier cosa que esté ausente, pero se manifiesta (puede ser vista o descrita); todo aquello que está ausente, pero constituye una alteridad" (2006, p. 16). Lo performativo es un acto deliberado, intencionado, que se construye y se representa mediante cierto tipo de actos contingentes con el fin de provocar, evocar, cierta experiencia en una comunidad determinada. Lo performativo nos habla de manera no explícita de los procesos de fabricación, técnicas de instrucción (script), límites necesarios entre lo público y lo privado, entre la "presencia" y la "ausencia manifiesta" y la alteridad (cambio de perspectiva por la del otro), entre otros aspectos. Lo performativo se ensambla y de paso se construye.

Cada vez que se ensambla y se construye lo performativo se consolida un marco creativo, ya que, cada individuo es un mundo particular, con un potencial creativo, que puede ser comprendido en términos de sus procesos de reconversión, astucias y autenticidades, aspectos que normalmente se utilizan para resolver algún tipo de situación y que perfilan un estilo muy particular de resolver las situaciones de borde. Cada persona tendrá un estilo de pensamiento y de acción muy particular en un esfuerzo por reencontrarse con una condición contingente matizada de originalidad, de novedad, de ingenio, integradas a aspectos tales como flexibilidad y fluidez, como parte característica de las negociaciones de unos actores mediados por unos objetos particulares, 
en un contexto sociocultural puntual y en un momento determinado harán florecer la creatividad.

Es gracias a este tipo de comprensión que se pudieron identificar cuatro resultados que dan respuesta a la naturaleza de la creatividad performativa, a partir de las acciones derivadas del proceder de Zaza-Drag y que constituyen la esencia de su performatividad como jugada creativa: entre lo público y lo privado, acentuando la exuberancia; llamar la atención, resaltando el destacarse y lo sencillo pero exagerado, destacando transgredir la cotidianidad, el último hace la referencia a los zapatos evocadores, resultados que detallaremos a continuación.

\section{Resultados}

A continuación, se detallan los cuatro resultados identificados como acciones performativas y creativas de Zaza-Drag.

\section{Entre lo público y lo privado}

La primera acción de la jugada que utiliza Zaza-Drag se instala en la exuberancia, no sólo formal-estética sino funcional, de los zapatos para Drag Queen. La exuberancia es notable y una constante tanto en la esfera de lo público como de lo privado. Para comprender, el abordaje de lo público y lo privado se realiza a partir de la hibridación empleada por Grossberg (2003, p. 155) quien describe tres imágenes de posibles existencias fronterizas de identidades, las imágenes: entre-medio, liminalidad y de intermediariedad. Siguiendo con Grossberg, las imágenes de un tercer espacio ven las identidades subalternas (drag / Zaza-Drag) como terceros términos únicos que definen un lugar entre-medio habitado, experimentado y explicado ya sea en lo público o en lo privado; las imágenes de la liminalidad disuelven la geografía del 
tercer espacio en la frontera misma; el subalterno vive, por decirlo así, en la frontera. Estrechamente relacionada con estas dos figuras de la hibridez está la del "cruce de fronteras" marca de una imagen de intermediariedad, que no construye un lugar o condición propios al margen de la movilidad, la incertidumbre y la multiplicidad del hecho mismo de cruzar constantemente las fronteras. Zaza-Drag o su comunidad drag, pueden asumir roles identitarios que los instalen en cada una de las imágenes hibridizadas, esto se logra de manera diacrónica, dependiendo de la esfera en la que está y en la que se quiere ubicar: ya sea pública o privada. El tercer espacio planteado en las imágenes entre-medio y la liminalidad equivalen a identidades situadas, referidas y direccionadas, ya sea entre lo público o lo privado, o de frontera entre las dos; las imágenes de la intermediariedad dan apertura a un umbral de tránsito, a cierto tipo de hibridación entre las esferas pública y privada. Transitar de lo privado a lo público, implica una actitud transgresora, una actitud a la que no le importen las fronteras, acorde a Gardner (2011, p. 89), los artistas, diseñadores, científicos, ingenieros contemporáneos quieren crear cosas, ponerlas a prueba, juguetear con ellas; no les preocupan las fronteras, ni siquiera se molestan en especificar el "comportamiento" al que pertenecen sus creaciones. La experiencia de uso del vestuario y de sus Zapatos para Drag Queen posibilitan que Zaza-Drag construya y constituya una actitud retadora al tiempo que recatada. Si los zapatos estuvieran siempre en la esfera de lo público, seguramente no trascenderían los paradigmas tradicionales o conservadores que direccionan cómo deben de ser los zapatos, sobre todo los zapatos para un hombre. Los zapatos responderían a aspectos de orden sociocultural, pero al tiempo responderían a aspectos de producción industrial en la que la serialización (taylorización) de los zapatos, marcaría la pauta. Pensando los zapatos como objeto, retomo las reflexiones de Gadamer (1991), acerca del objeto como constructo político - económico - industrial: 
el objeto es la herramienta de realización de voluntades del ser y es una de las formas del mito industrial — para toda receta su plato, para todo trayecto un medio de transporte, para cada música su cadena de alta fidelidad, para cada compositor su instrumento, para cada enfermedad un remedioPara actuar en esta sociedad se necesitan herramientas, objetos. La sociedad fabrica, entonces, los objetos —esa es su significación-y estudia el conjunto de deseos reales o potenciales de un "público blanco" que es coextensivo a ella misma en un mercadeo ilimitado que persigue como meta una adecuación siempre más perfecta entre los deseos imaginables de todos, o de algunos, y la fabricación, el surtido ir a ostentación de los productos. (Gadamer, 1991, p. 63)

El ámbito de lo privado provee la atmósfera adecuada para la aparición de los "Zapatos Drag Queen". A ojos de lo público, los zapatos para Drag Queen están asociados a un aura de misterio, pero al mismo tiempo de contradicción: el primer carácter origina cierto tipo de rechazo por ser considerados como objeto de fetiche o de culto; el segundo carácter se asocia con el sentido común y la relación de los zapatos Drag Queen con baja funcionalidad a la hora de desplazarse, incomodidad traducida en bajos niveles de confort $y$, seguramente la que más pesa en términos de pregunta, ¿qué hace un hombre en los zapatos de una mujer? En búsqueda de sentido, detallemos con atención a Zaza-Drag un hombre de mediana edad que se mueve con un carácter muy especial, en el mundo drag. "Mi nombre artístico es Zaza Drag o Zaza, tengo edad 35 años, soy un personaje muy cómico en el mundo en el que me muevo, el mundo del Drag" (Zaza Drag, comunicación personal, 17 de noviembre de 2016).

La hibridación la revela Zaza-Drag como una imagen de intermediariedad entre lo público y lo privado, y la disociación entre lo que se debe representar como hombre y lo que quiere representar como mujer.

la comunidad LGBT vive muy escondida, entonces un personaje, como lo que soy no lo hago, ya que como le comentaba afuera soy un personaje muy público mi empresa muy reconocida, mi familia, entonces cuando tomo el papel de Zaza Drag, me gusta llamar la atención. (Zaza Drag, comunicación personal, 17 de noviembre de 2016) 
Zaza-Drag empieza a revelar una personalidad base, que hace parte de su mundo, presentando una postura como individuo que le gusta llamar la atención, pero también como perteneciente de la comunidad drag. Así lo fundamenta Dubet (2010, p. 103): el individuo ha hecho tan suyas, en el curso de la socialización primaria y profunda, las expectativas del prójimo, transformando esa identidad en una especie de naturaleza. La noción de "personalidad de base" se traduce como un nivel de acción que puede tener sentido en la medida que el individuo ha encarnado los códigos sociales elementales de la comunidad a la que pertenece o quiere pertenecer. Así las cosas, la identidad se experimenta como una atribución social gracias a que Zaza-Drag está constituido como un ser social. Zaza-Drag nos enseña que hay categorías drag. Según sus palabras existen "transformistas y transgeneristas". Los transformistas serán aquellos hombres que, gracias a la integración de cierto tipo de aditamentos (zapatos, ropa, pelucas y maquillaje), aunado a gestos y posturas, consolidan una corporalidad semejante a la de una mujer.

(...) yo puedo ser un transformista. Desde las seis de la mañana a las diez de la noche yo soy un hombre, aspecto de hombre, me visto como un hombre. Llegando ya la noche me transformo en una mujer, muy femenina, muy lente, muy cabello, con ademanes muy femeninos, ese es el transformista. (Zaza Drag, comunicación personal, 17 de noviembre de 2016)

Cuando termina su performance, los transformistas vuelven a ser hombres. Ellos tienen claridad en cuanto a los momentos en los que deben ser hombres y los momentos en los que representan a la mujer. La condición de misterio del Drag Queen se acentúa, ya que las transformaciones se suceden en la noche de manera recurrente. "(...) entonces el Drag entra en el papel del transformista, porque nosotros empezamos un proceso a partir de las nueve de la noche, empezamos a cambiar, sin perder nuestra parte, entre masculino y femenino" (Zaza Drag, comunicación personal, 17 de noviembre de 2016) 
Por otro lado, los transexuales — denominados transgeneristas por Zaza-Dragson radicales, ya que en sus cuerpos han mediado una serie de intervenciones quirúrgicas que apuntan a la transformación del cuerpo de un hombre en cuerpo de una mujer. "(...) el transgenerista es el que está todo el día, prácticamente, vestido de mujer, el cabello, ya llegan hasta el punto de operar sus partes íntimas" (Zaza Drag, comunicación personal, 17 de noviembre de 2016)

Zaza-Drag nos brinda pistas en cuanto a cómo perfilan diversas retóricas a partir de la consolidación de diversas estrategias de su performance, de tal manera que cada performance "Ilame la atención", sea impactante. Entre otras tenemos: los Drag de concurso, los Drag de desfile y los Drag que se ganan la gente.

(...) hay Drag de concurso que les gusta llamar la atención, Drag de "mírame y no me toques" (...) no soy de show, pero lo hago por sentirme bien, en ocasiones como un Halloween o un desfile del orgullo gay, donde participo y he participado en varias ocasiones como cinco veces, cada desfile Ilamo la atención, me dicen "tomate la foto conmigo" soy muy payaso, muy exagerado, como tal, ese es Zaza Drag. (...) cuando yo estoy en ese personaje, soy muy chistoso, reírme con la gente, a "mariquiar" con la gente, a ganarme la gente, ¡hola que más! Quieres la foto muy natural, muy casual, ¿Cómo la quiere? Una foto vale 5.000 pesos. Pero espera un momento, "tócame, bésame, hazme tuya", cosas como esas. (Zaza Drag, comunicación personal, 17 de noviembre de 2016, énfasis del autor)

El mundo drag es un mundo complejo, es el mundo de frontera y de transgresión, de liminalidad y de intermediariedad, buena parte de esta investigación estará más ligada a los Drag Queen como potenciales y marginales actores que agencian la comunidad drag. Lo anterior no implica que se reconozcan la totalidad de las relaciones e influencias o afectaciones que la comunidad drag ejerce sobre sus individuos. 


\section{Llamar la Atención}

La segunda acción se instala en el Ilamar la atención, que para el drag es fundamental. Llamar la atención se fundamenta en el deseo de "destacarse" de las esferas claramente delimitadas de lo privado y lo público, destacarse implica una condición identitaria de intermediariedad. Es la manera de garantizar su visibilidad desmedida, haciéndose sentir, ver, oír. Zaza-Drag es capaz de destacarse, constituyendo diversas estrategias para Ilamar la atención, construyendo un conjunto de retóricas, no solamente argumentativas, sino de tipo formal, gestual, corporal, temporo-espacial, entre otras, en las que consolida una atmósfera (gala) que la rodea y la caracteriza en términos de "exageración" agenciada por la comicidad.

me gusta llamar la atención: los colores, la exageración, muy cómico, muy de risa, muy chévere, muy jocoso, pero sin ir más allá de faltar el respeto, siempre lo he tenido, porque en la comunidad LGBT siempre hay roces que el transformista, que nosotras ridiculizamos al transformista, para mí no es ridiculizarlo. (Zaza Drag, comunicación personal, 17 de noviembre de 2016)

Zaza-Drag constituye retóricas de la mano de un arsenal de estrategias, sabe traducir de manera adecuada cada situación para hacerse notar. Su estrategia se instala directamente en los zapatos, los cuales potencian acciones directas en el marco de una performance transgresora de las costumbres conservadoras de la sociedad. Al mismo tiempo, tiene muy claro unos límites demarcados por el respeto a la mujer.

para mi es exagerar un poco más las partes femeninas, con el sentido de humor de picardía, de exageración, pero ante todo con el respeto. Porque reconozco que vengo de una mujer, tengo muchas mujeres en mi familia, por ende, al cual aprecio y admiro, entonces nunca me considero una mujer, trato de evitar y resalto la parte chistosa de la mujer. (Zaza Drag, comunicación personal, 17 de noviembre de 2016) 
De las muchas maneras para llamar la atención quisiera primero centrarme en el vestuario y, específicamente, en la naturaleza identitaria de los Zapatos Drag Queen. Los zapatos hacen parte de la estrategia de Zaza-Drag para comunicar sin palabras. Comunicar su mundo interior, lo que es, lo que la hace Drag Queen, y lo que la diferencia de otros individuos. Es diciente la manera cómo el drag expresa su sentir de vida vivida, su mundo. En una entrevista en un programa de televisión argentina, Drag-Le Brooks y Drag-Less, ante la pregunta ¿Qué es un Drag Queen? Drag-Le Brooks responde: “Una Drag Queen es usar tu cuerpo como lienzo para crear un imaginario tuyo personal y jugar con el género" (Eltrece, 2017).

Mientras que Drag-Less responde:

Un personaje propio muy artístico que exagera lo femenino que hay en el cuerpo masculino (...) Es una expresión de la esencia de uno, creo que el Drag es artístico. En mi caso lo llevo como la esencia personal mía. Mi Drag es como todo, todo lo que quiero expresar y, que como civil o varón jamás lo haría y, te da la seguridad. (Eltrece, 2017)

Drag-Le Brooks define su condición drag a partir de la actuación, de esta manera consolida la transformación drag a voluntad de quien lo quiera realizar. No tienes que ser gay para ser Drag ya que somos actores, estamos actuando. En tanto, Drag-Less demarca su decisión a partir del "trascender reglas", al tiempo que aterriza la decisión relacionándola con el trabajo. "Cuando la persona tiene ganas de trascender las reglas que hay frente al género, más allá de la elección sexual. En la semana somos varones, esto es un trabajo" (Eltrece, 2017).

Sobre la misma línea, Drag-Eiko deja bien claro la dificultad de vivir de la actuación Drag, más aún, la instala en términos de hobby, de esta manera recomienda que es necesario combinarla con otras actividades, por ejemplo, estudio, trabajo. 
Esto es un hobby muy bonito espectacular, pero es un hobby, hay gente que puede vivir de ello, como hobby. Pero hay que tener prioridades: hay que tener estudios, hay que tener trabajo. De esto comes un día, comes dos o un mes, pero no todo el año seguido. (Eltrece, 2017)

De esto hablan los drag, de las dificultades para consolidar su experiencia drag. Hablan de la identidad de cada uno de ellos, a la vez que demarcan sus diferencias al interior de su comunidad drag. Consolidan su experiencia, a partir de una serie de transformaciones controladas, representaciones fragmentadas de situaciones y acciones que le darán base de experiencia a la historia que se quiera contar. Haraway propone una figura constituida de muchas figuras fragmentadas, una figura semejante a la imagen de un cyborg como "una potente subjetividad sintetizada a partir de la fusión de identidades marginales" (1995, p. 174). Mientras que para Grossberg (2003):

\footnotetext{
la fragmentación enfatiza la multiplicidad de identidades y posiciones dentro de cualquier identidad. Las identidades podrían ser, entonces, contradictorias, y están compuestas por fragmentos parciales. Las teorías de fragmentación pueden concentrarse en la fragmentación de identidades individuales o de las categorías sociales (de diferencia) dentro de las cuales están situados los individuos, o en alguna combinación de unas y otras. (p. 155)
}

En la misma línea, Krippendorff plantea cómo todos los artefactos "support various identities" (soportan varias identidades) (2006, p. 162). Los zapatos Drag Queen pueden soportar varias identidades, no solamente los diversos roles del drag acorde al aura de la performance desarrollada, sino que relaciona a quienes los han diseñado y producido, a quienes como público en general asisten a las "galas" o performance.

En otras palabras, la constitución y construcción de identidad de ZazaDrag implican una apropiación del estilo drag, resignificado en términos estéticos por Zaza-drag, esto involucra una dinámica constructiva y variable del mundo drag. Zaza-Drag, como agente transformador y transformado, trasciende el hecho que los zapatos Drag Queen no sean un simple disfraz, 
un simple remedo de una imagen. Lo que quiere mostrar es que no haya distancia entre lo que cubren los zapatos y lo que realmente es Zaza-Drag. Los atributos drag hablan del espacio socio-estético y dominante, hablan del "estilo", para luego derivar a modos como Zaza-Drag constituye sus retóricas. El carácter identificador y diferenciador tiene que relacionarse, como lo retoma Gadamer (1991, p. 60), con la experiencia estética, el gusto representa un momento nivelador. Momento caracterizado como "sentido común". Es así como trascendemos el gusto en términos de estilo, el estilo drag dará cuenta de "eso" que diferencia, hablará de la naturaleza del drag como colectivo, pero al mismo tiempo posibilitará distinguir el carácter común de Zaza-Drag. En cuanto al estilo, Gardner (2011, p. 67) lo utiliza para distinguir las obras de una era con respecto a las de otra. Decisiones en torno a preferencia de colores, texturas, hablan directamente de la identidad y del estilo de quien los escoge, para este caso Zaza-Drag:

Colores muy Ilamativos, entre más colores más Ilamativos la idea es Ilamar la atención. Yo siempre he utilizado colores muy fuertes, hay temporada de colores ácidos, en estos momentos me gustan colores Ilamativos, el amarillo, el rojo, para que donde yo pase, se diga allá va un Drag o me identifique, ese es Zaza Drag, como me llaman mis amistades. (Zaza Drag, comunicación personal, 17 de noviembre de 2016)

Parafraseando a Baudrillard (1997, p. 14), el estilo dará cuenta de la "presencia" de los objetos, así que los zapatos Drag Queen personifican las relaciones humanas, Ilenan el espacio que comparten y poseen un alma. Además, seres y objetos están ligados, y los objetos cobran en esta complicidad una densidad, un valor efectivo que se ha convenido en llamar su "presencia". Los zapatos Zaza-Drag son interesantes estéticamente, porque tienen una presencia drag. Zaza-Drag lo reafirma cuando habla de "la belleza de sus zapatos". La belleza como adjetivo, que denota no solamente objetos — como es el caso de sus zapatos-, sino de sus relaciones con personas (drag), acontecimientos (concursos, desfiles entre otros) pero, sobre todo, un conjunto de experiencias. 
Es Gadamer quien usa lo bello como puente. La función ontológica de lo bello consiste en cerrar el abismo abierto entre lo ideal y lo real. En un mismo proceso continúa diciendo: "extraemos con la vista, por así decirlo, la imagen de las cosas y nos figuramos su imagen en ellas. Y así, es la imaginación, la facultad del hombre para figurarse una imagen, la facultad a la que se orienta sobre todo el pensamiento estético" (1991, p. 52).

Las maneras de llamar la atención estarán marcadas por performances cuyo valor estético es alto, pero - al mismo tiempo- por cierto, tipo de aura de la naturaleza del mundo drag. Por la condición humana de cada uno de los Drag y por la apariencia de todo su mundo drag, instalado en la exageración calculada. La exageración es la metáfora circundante que cualifica cada una de las performances. Tomemos el ejemplo de la Gala, presentada por Drag-Sethlas²: en el marco del Carnaval de Las Palmas (Gran Canaria, España) representa en su performance una virgen y la crucifixión de Cristo. El periódico El país reseña la noticia de la transgresión de la siguiente manera.

\footnotetext{
Drag Sethlas se ha proclamado esta noche nuevo Drag Queen de Las Palmas de Gran Canaria con un número transgresor que encendió al público del certamen en su 20 aniversario y que no va a dejar indiferente a nadie, por sus referencias religiosas a la Virgen y a la crucifixión de Cristo. Llegó literalmente como una virgen —vestido como una imagen de María y a ritmo de "Like a prayer" de Madonna-, pero no fue ningún milagro que Sethlas se coronase Drag Queen del carnaval de la capital grancanaria, dedicado este año a "La eterna primavera". (El País, 2017)
}

Gracias a la exageración, los drag muestran lo que son y lo que quieren representar en sociedad. La visibilidad como constructo, nos muestra decisiones que para el público en general pueden pasar desapercibidas o ser escandalosas, sobre todo, cuando la performance, con su naturaleza trasgresora, provoca valores conservadores.

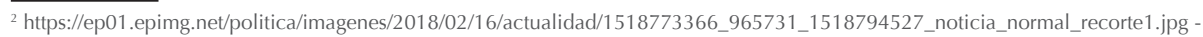




\section{Lo "sencillo pero exagerado"}

La tercera acción se instala como "modo de Ilamar la atención" de los Drag: trasgrediendo la cotidianidad de las situaciones conservadoras, no respetando fronteras socioculturales preestablecidas, recontextualizando los ámbitos de aparición y de actuación entre lo público y lo privado. Se llama la atención, ya sea con la pretendida diferencia de una performance, con el fortalecimiento de un conjunto de gestos y posturas, con el desarrollo de un vestuario necesario para hacer creíble cada una de sus galas. El drag Ilama la atención apoyado principalmente en el uso y la exhibición de sus zapatos Drag Queen. Los zapatos Drag Queen son indelebles a la naturaleza drag, es una manera en la que se ha dispositivado dicha naturaleza, razón por lo cual su entendimiento posibilita una comprensión extendida del drag.

A diferencia de Drag-Sethlas, que construye retóricas transgresoras a partir de iconos religiosos conservadores de la cultura, Zaza-Drag muestra un poco de "recato" en la apariencia de su vestimenta, más no de sus Zapatos Drag Queen. Corporalmente constituye una estética policéntrica, con dos centros de atención potentes, aspectos que complementa en la dinámica de su performance. Zaza-Drag sabe llamar la atención a su manera, pero condicionada a que "todo sea sencillo", es decir, ella no es afín a estéticas recargadas, no gusta de los grandes vestidos, "es alérgica a los encajes" — aspecto importante ya que el juego de encajes en los vestidos es muy femenino-. En términos estéticos, su vestimenta tiende a ser minimalista; la integración compositiva de sus zapatos, cabeza y corporalidad —expresada en sus gestos y movimientos-, son exagerados. Encuentro alguna forma de transgresión allí.

Lo importante es Ilamar la atención. Por ejemplo, en las últimas ocasiones he ido muy... Eso también va con la personalidad, ¿Qué pasa? Yo soy muy brincón, en el sentido que me gusta bailar, recochar, caminar, correr, soy muy posudo. No me gustan los trajes que me cohíban de eso. Hay personas que utilizan sus vestidos grandes, que no se pueden ni mover, o que la mano debe llevar un encaje, 
yo soy alérgico a eso. Yo soy más de flexible, que todo sea más sencillo, sencillo pero exagerado. Sencillo pero pegado a mi cuerpo, que pueda moverme, brincar, reírme, dar vueltas, tirarme al suelo si me toca, postrarme en un sofá, levantar las piernas, entonces siento que eso me da la facilidad a mí como personaje. (Zaza Drag, comunicación personal, 17 de noviembre de 2016, énfasis del autor)

Zaza-Drag constituye su performance a partir de la funcionalidad de su vestimenta. Se instala en la flexibilidad del cuerpo, en los diversos grados de libertad que le permite su vestimenta, pero sobre todo sus zapatos. Mostrar su cuerpo, usarlo para agenciar una personalidad divertida, extrovertida, en sus términos "recochera". Paradójicamente, la dinámica de su corporalidad es compleja en el sentido de la cantidad de micro acciones (pliegues y dobleces) que tiene que realizar para constituir el personaje que está desarrollando.

Mi perfil lo hallo así, Mientras que hay amigos que les gusta utilizar el gabán larguísimo y llegar así. No yo no utilizo eso, yo soy, bueno me quite uno y quede como voy a quedar: un enterizo pegado al cuerpo o un vestidito corto, no me gusta tanta arandela para moverme en el escenario. El público cuando voy a un evento a una discoteca, que pueda recochar, a eso me refiero. Yo soy así, dependiendo de la personalidad. (Zaza Drag, comunicación personal, 17 de noviembre de 2016)

Zaza-Drag es así dependiendo de su personalidad, pero también dependiendo del ámbito en el que va a suceder la performance, por ejemplo, Zaza-Drag pública, de Facebook y de eventos masivos, se muestra diferente. Para lo cual véase la Figura 3. 


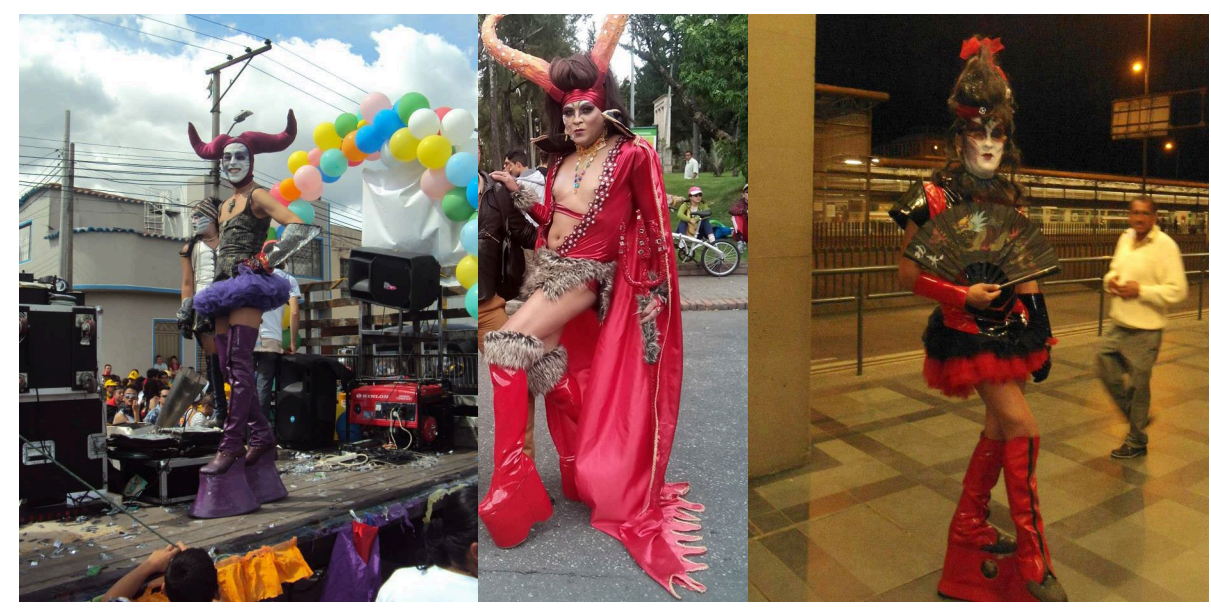

Figura 3. Zaza-Drag Fuente: Imágenes tomadas del muro de Facebook Drag Valeri-Zaza en 2017: https://www facebook.com/profile. php?id=100005126956208\&hc_ref=ARTyPymlmybVrnaprUpBS9re7L1AZYeRByHhYRhpTrm9TodCA2zpVeclHSXnuMS8BhQ

Hemos hablado de la naturaleza del mundo drag, de la condición humana de Zaza-Drag, queda por último detallar la apariencia de sus Zapatos Drag Queen. Lo performativo de los zapatos se manifiesta en la evocación como uno de los tres instrumentos de análisis de la belleza desarrollado por Gardner (2011, p. 71), por el alcance de este artículo me concentraré únicamente en desarrollar este aspecto.

\section{Los Zapatos evocadores}

La cuarta acción se instala en los zapatos que convocan gracias a la recordación instalada en su apariencia. Hablo entonces de la memorabilidad de su forma. La memorabilidad está plasmada en términos definidos por Gadamer (1991, p. 96) cuando discute cómo en la representación no se trata de que la obra 
represente algo que ella no es; la obra no es una alegoría, sino que sólo en ella misma puede encontrarse lo que ella tenga que decir. Para que la recordación sea efectiva en los Zapatos Drag Queen, la imagen ha de ser coherente con el estilo drag, pero resignificado a la condición de cada drag. Hablo de la negociación entre mundos estilísticos, entre estéticas: una estética que se instala en imágenes con un sentido de "visibilidad trasgresora" que favorecen el uso de modos, tales como la 'exageración calculada' o el engrandecimiento de algunos aspectos femeninos manifiestos en el cuerpo del hombre-Drag, aspectos que han sido opacados por incidencias socioculturales. En cuanto a preferencias o gustos, por ejemplo, Doña Teresa ${ }^{3}$, cualifica las preferencias de forma y material del tipo de zapato.

Doña Teresa: Claro, ellos traen, de hecho, ellos traen muchos estilos, muchas ideas, ellos les gustan los moños, ellos se inventan muchas cosas raras, claro que sí.

Samuel: ¿Algún color que recuerde?

Doña Teresa: El plateado y el dorado, para ellos. (M. T. Hurtado de Aristizábal, comunicación personal, 28 de octubre de 2015

En cuanto a la gama de colores, no es el reino del color pastel, ya Baudrillard (1997, p. 34) reflexionaba en torno a cómo el color pastelizado quiere ser un color vivo, pero no es más que un signo moralizado. En cuanto a los colores Ilamativos, plantea que el color vivo es vivido siempre como signo de emancipación: de hecho, compensa a menudo la falta de cualidades más fundamentales. Los colores "chillones" lo miran a uno. Si se pone uno un vestido rojo, está desnudo, se convierte en objeto puro, carente de interioridad. En relación con el status social de objeto que tiene la mujer, el vestido femenino se inclina más particularmente por los colores vivos. Doña Teresa particulariza aún más la observación, centrando la atención en el cambio de altura y en cómo el uso de tacones veinte y medio los enloquecía. 
A ellos no les importa los materiales, realmente. A ellos les importa que sean vistosos, charoles, plateados, dorados, tacones 20 y medio. Yo fui la primera que saqué tacones 20 y medio y ellos cuando veían esos tacones 20 y medio... Por ejemplo, iyo mandaba hacer unas botas número 42 en tacón 20 y medio y las ponía en la puerta y no! Se enloquecían con esos tacones. Para ellos es muy importante estar subidos en tacones, estar con cremalleras doradas, herrajes dorados, cosas vistosas (...) Téngales plateado y dorado y como piedras, eso le encanta. (M. T. Hurtado de Aristizábal, comunicación personal, 28 de octubre de 2015)

El cambio de altura implica de entrada marcar diferencia frente a otras personas, hace que las piernas se perciban mucho más largas de lo común y, aunque puede ser una limitante en términos de movilidad corporal, su uso continuo va perfilando un carácter identitario y diferenciador del mundo Drag. Otra lectura importante es la que hace doña Graciela Barrios, administradora de Calzado Yara Aristizábal, en cuanto a las preferencias del mundo drag:

Ellos son un poco escandalosos, les gusta más los brillantes, les gustan con cadenas, tacones bien altos, son más exigentes en el tipo de material como brillantes, escarchados, plateados, esos colores son los que más les gustan a ellos. (Graciela Barrios, comunicación personal, 29 de octubre 2016)

\section{Doña Rosa Tocancipá ${ }^{4}$, aporta recordándonos la importancia del manejo de la luz en los Zapatos Drag Queen, los reflejos, los brillos, las escarchas, entre otras:}

Pues a ellos les gusta los colores. Brillos. Alturas. Eso es lo que más importa. Yo me acuerdo que de los primeros zapatos que se hicieron fue a un diseñador Antonio, era un peluquero, que quería concursar en Nueva York, pues él tenía su peluquería aquí y allá, se me escapa el apellido, él fue de los primeros que se le hizo una bota que parecía un casco de vaca, fue espectacular, él quedo super contento. De los clientes que mandaba él, pues extasiados con esa forma como le quedo, porque él se iba a disfrazar mitad hombre mitad animal, entonces ese disfraz fue espectacular, entonces, de los que más recuerdo es él, y ya después lo que ellos buscan es altura, colores, así cosas muy llamativas. (R. Tocancipá, comunicación personal, 29 de octubre de 2016) 
Los Zapatos Drag Queen se hacen "memorables" visualmente al apoyarse en recursos formal-estéticos: cambio de altura, accesorios vistosos, tonos dorados y plateados, piedras, moños, entre otros, son recursos usados de manera 'alineada' para consolidar en los zapatos una especie de aura que a la vez identifique y diferencie. Está en la misma línea planteada por Gardner (2011, p. 72) cuando propone "ciertas trayectorias de interés", cada vez que una visión, una experiencia, resulta familiar, los individuos apartan la mirada o dejan de prestar atención, por lo tanto, para mantener el interés, es preciso elevar constantemente la apuesta. Además de recordarnos el poderío que tiene la evocación cuando se quiere que algún elemento de interés se manifieste en una forma. Se puede hablar de otra estética derivada de la anterior, que pretende consolidar un manifiesto que demarque la presencia y actuación de un drag frente al auditorio. Ese manifiesto particular dará cuenta de los modos de traducir dicha identidad particular drag, para un contexto determinado. Revisemos como Zaza-Drag se manifiesta.

En estos momentos lo podemos ver, mírame, el tamaño del zapato, del tacón, de los aretes, de la peluca. Por ejemplo, el último atuendo que utilice fue una trusa muy pegada al cuerpo, con un afro en la cabeza supremamente gigante, que ninguna mujer lo utiliza, mis botas, aparte un cachetero con un cuerpo muy proporcionado y muy grande. (Zaza Drag, comunicación personal, 17 de noviembre de 2016)

De entrada, Zaza-Drag reta a ser vista. 'Mírame' implica un estoy aquí, una especie de grito para llamar la atención. El 'estar aquí' denota un esfuerzo que se apoya en cierto tipo de comprensión estética. Marca la diferencia con el estilo diferenciador de sus zapatos y por el tamaño de los tacones, siguiendo con la cabeza, sus aretes, su peluca, como preceptos formales compensan simétricamente la alta tensión llamativa de los zapatos Drag Queen. Luego el cuerpo. Como puente entre los pies y la cabeza, el uso de una "trusa muy pegada al cuerpo" hace destacar el cuerpo "sencillamente, pero de manera exagerada". La corporalidad de Zaza-Drag es compositiva cuando integra a 
su discurso y acción performativa el carácter grande del cuerpo masculino, pero a la vez proporcionado que busca convocar, al menos metafóricamente, el cuerpo de la mujer. Zaza-Drag no busca ser una mujer, más bien quiere representarla.

No me siento mujer yo sigo siendo hombre, en mí nunca ha estado el colocarme senos ni de operarme, no va, porque no está en mis parámetros, por mi cultura, porque me considero un gay que no voy hasta allá, respeto a los que se han operado, pero no lo disfruto. (Zaza Drag, comunicación personal, 17 de noviembre de 2016)

Zaza-Drag procura hacer una mímesis exagerada de la belleza femenina. Busca llamar la atención resolviendo la composición a partir de lo que no está, compensando los vacíos femeninos: por ejemplo, el manejo de la ausencia de los senos se manifiesta en dos aretes "súper-gigantes" que emulan los senos femeninos:

Es exagerar la belleza femenina. Los aretes, por ejemplo, nosotros utilizamos los aretes o la primera vez que lo hice fue dos campanas de navidad super gigantes, imitando los senos de una mujer, pero vuelvo y recalco, sin faltarle el respeto a la mujer, porque eso es lo que no queremos (...) nosotros nos vamos por la parte jocosa, chistosa de la mujer, exagerándola. Grande. (Zaza Drag, comunicación personal, 17 de noviembre de 2016)

El mismo vacío que ha servido para exagerar, puede ser utilizado de manera redundante para acentuar, para tensionar doblemente. Para exagerar lo exagerado.

Un Drag es demasiado, técnicas de la moda. Podemos ver un Drag que no utiliza senos, todo es exagerar la moda. Por ejemplo, para el próximo evento en que voy a participar, no, por lo general no llevo senos, no llevo espumas, porque no somos transformistas. Somos muy natural, no perdiendo la esencia del hombre, entonces, por lo general el Drag nunca lleva senos. A veces por exagerar, colocamos dos campanas de senos y dos campanitas pequeñas de aretes. A veces no utilizo aretes o coloco una flor grande, porque hay que exagerar lo que la mujer utiliza, en forma exageradamente. (Zaza Drag, comunicación personal, 17 de noviembre de 2016) 
Los Zapatos Drag Queen son el centro performativo que convoca hacía la memorabilidad creativa gracias a las diversas estrategias que han alineado para llamar la atención; a partir de dicho centro se constituyen orbitales, tales como, el vestuario, la performance, el espacio de presentación, el auditorio, entre otros.

\section{Conclusión}

No existe una única manera de abordar la creatividad. La creatividad se manifiesta como campo epistemológico que posibilita que la naturaleza de las relaciones contingentes de quien se aproxima a resolver una situación, una gala o un acto, dependa en buena medida de su visión de mundo, de su identidad y de su estilo de pensamiento. La perspectiva de lo creativo en este escrito no se refirió a identificar las capacidades de ciertos individuos de develar verdades ocultas, más bien reflejó que en un ambiente (Calzado Yara Aristizábal) y objeto señalado (Zapatos), se tejieron una serie de relaciones, se potenciaron negociaciones en torno a los actos performativos y contingentes que involucran la identidad de diversos actores para develar los grados de inclusión en una red sociocreativa. Gracias a la aproximación vía la creatividad situada, se pudieron comprender las lógicas de construcción hechos performativos por Zaza-Drag, que dieron cuenta de su naturaleza de mundo, de su condición humana y del porqué de la apariencia de sus Zapatos Drag Queen. Esto implicó revisar el carácter de sus procesos de reconversión, sus astucias y sus autenticidades, traducidas, estas tres, en términos de su estilo, y reveladas a partir de la contingencia de las acciones de mundo de Zaza-Drag: "entre lo público y lo privado" desde la exuberancia; "llamar la atención" desde el destacarse; "lo sencillo pero exagerado" desde la transgresión de la cotidianidad. Éstas dan cuenta de la naturaleza de su "estilo de pensamiento" como jugada — paralogía- construida cuando desde lo creativo y performativo al mundo. 


\section{Bibliografía}

Baudrillard, J. (1997). El sistema de los objetos (F. González Aramburu, trad.). México D.F.: Siglo veintiuno editores.

Bauman, Z. (2003). De peregrino a turista, una breve historia de la identidad. En S. Hall \& P. du Gay (comps.), Cuestiones de identidad cultural (pp. 40-68). Buenos Aires: Amorrortu.

Butler, J. (2007). El género en disputa: el feminismo y la subversión de la identidad (M. A. Muñoz, trad.). Barcelona: Paidós Ibérica.

Dubet, F. (2010). Sociología de la experiencia (G. Gatti, Trad.). Madrid: UCM Editorial Complutense.

El País. (1 de marzo de 2017). El carnaval de Las Palmas corona una provocadora Virgen Drag. https:/elpais.com/elpais/2017/02/28/ videos/1488268329_627232.html

Eltrece. (13 octubre 2017). ¿Qué es ser una Drag Queen? [Video]. Youtube. https://www.youtube.com/watch?v=pAzeOZMJexc

Escobar, A. (2007). La invención del tercer mundo: construcción y deconstrucción del desarrollo. Bogotá, Colombia: Grupo Editorial Norma.

Fleck, L. (1986). La génesis y el desarrollo de un hecho científico (L. Meana, Trad.). Madrid: Alianza Editorial.

Fressoli, M., Lalouf, A. y González, M. (2006). Mapas o Pinboards. Re-construyendo la realidad en un espacio de coordenadas preestablecidas. Una entrevista con John Law. Redes, 12(24), 91-113. https://ridaa. unq.edu.ar/bitstream/handle/20.500.11807/620/04-R2006v12n24. pdf? sequence $=1$ \&isAllowed $=y$ 
Gadamer, H. G. (1991). La actualidad de lo bello (A. Gómez Ramos, Trad.). Barcelona: Paidós.

García Canclini, N. (1998). Culturas Híbridas: estrategias para entrar y salir de la modernidad. Mexico D.F: Grijalbo.

Gardner, H. (2011). Verdad, belleza y bondad reformuladas: la enseñanza de las virtudes en el siglo XXI (M. Pino Moreno, Trad.). Barcelona: Paidós.

Grossberg, L. (2003). Identidad y estudios culturales: ¿no hay nada más que eso? En S. Hall \& P. du Gay (eds.), Cuestiones de identidad cultural $(\mathrm{H}$. Pons, trad.) (pp. 148-180). Buenos Aires: Amorrortu.

Gieryn, T. (1983). Boundary-work and the demarcation of science from nonscience: strains and interests in professional ideologies of scientifics. American Sociological Rewiew, 48, 781-795.

Goyes Narváes, J., Rodríguez Rodríguez, C., y Victorino Ramírez, A. (2017). Memorias del proyecto LEM Guaviare: Lectura y escritura con medios. Guaviare, Colombia: Nomos Impresores.

Guber, R. (2001). La etnografía: método, campo y reflexividad. Bogotá, Colombia: Grupo Editorial Norma.

Hall, S. (2003). ¿Quién necesita "identidad"? En S. Hall \& P. du Gay, Cuestiones de identidad cultural (H. Pons, trad.) (pp. 13-39). Buenos Aires: Amorrortu.

Hammersley, M. \& Atkinson, P. (1994). Etnografía: métodos de investigación (M. Aramburu Otazu, trad.). Barcelona: Paidós básica.

Haraway, D. J. (1995). Ciencia, cyborgs y mujeres: la reinvención de la naturaleza (M. Talens, trad.). Madrid: Ediciones Cátedra. 
Herrera, S. (28 de 10 de 2019). Umbrales de la creatividad: construcción social de conocimiento creativo en algunas micro - pequeñas organizaciones productivas mipymes (Tesis de Doctorado). Doctorado en Ingeniería: Industria y Organizaciones, Universidad Nacional de Colombia. https://repositorio.unal.edu.co/handle/unal/77155

Krippendorff, K. (2006). The semantic turn. Florida: Taylor \& Francis.

Kuhn, T. S. (1998). La estructura de las revoluciones científicas (A. Contin, trad.). Santafe de Bogotá: Fondo de la cultura económica.

Lyotard, J. F. (1994). La condición postmoderna. Barcelona: Catedra.

Restrepo Forero, O. (2007). Evolución, darwinismo y religión: Debates, estereotipos y fronteras móviles. En Adarve \& Tejeiro, C. (Ed.), Creer y poder hoy (pp. 243-272). Bogotá: Universidad Nacional de Colombia.

Taylor, S. J. \& Bogdan, S. (1987). Introducción a los métodos cualitativos de investigación: la búsqueda de significados (J. Piatigorsky, trad.). Barcelona: Ediciones Paidós.

Cómo citar: Herrera-Castiblanco, S. A. (2021). La creatividad performativa. Revista KEPES, 18(23), 111-146. https://doi.org/10.17151/kepes.2021.18.23.5 